University of Nebraska - Lincoln

DigitalCommons@University of Nebraska - Lincoln

2010

Concurrent simulation of the eddying general circulation and tides in a global ocean model

Brian K. Arbic

Florida State University, barbic@fsu.edu

Alan J. Wallcraft

Stennis Space Center, wallcraft@nrlssc.navy.mil

E. Joseph Metzger

Stennis Space Center, metzger@nrlssc.navy.mil

Follow this and additional works at: https://digitalcommons.unl.edu/usnavyresearch

Arbic, Brian K.; Wallcraft, Alan J.; and Metzger, E. Joseph, "Concurrent simulation of the eddying general circulation and tides in a global ocean model" (2010). U.S. Navy Research. 27.

https://digitalcommons.unl.edu/usnavyresearch/27

This Article is brought to you for free and open access by the U.S. Department of Defense at DigitalCommons@University of Nebraska - Lincoln. It has been accepted for inclusion in U.S. Navy Research by an authorized administrator of DigitalCommons@University of Nebraska - Lincoln. 


\title{
Concurrent simulation of the eddying general circulation and tides in a global ocean model
}

\author{
Brian K. Arbic ${ }^{\mathrm{a}, *}$, Alan J. Wallcraft ${ }^{\mathrm{b}}$, E. Joseph Metzger $^{\mathrm{b}}$ \\ a Department of Oceanography and Center for Ocean-Atmospheric Prediction Studies, Florida State University, Tallahassee, FL 32306, United States \\ ${ }^{\mathrm{b}}$ Oceanography Division, Naval Research Laboratory, Stennis Space Center, MS, United States
}

\section{A R T I C L E I N F O}

\section{Article history:}

Received 23 June 2009

Received in revised form 20 January 2010

Accepted 22 January 2010

Available online 1 February 2010

\section{Keywords:}

Eddies

Internal tides

High-resolution ocean models

\begin{abstract}
A B S T R A C T
This paper presents a five-year global simulation of HYCOM, the HYbrid Coordinate Ocean Model, that simultaneously resolves the eddying general circulation, barotropic tides, and baroclinic tides with 32 layers in the vertical direction and $1 / 12.5^{\circ}$ (equatorial) horizontal grid spacing. A parameterized topographic wave drag is inserted into the model and tuned so that the surface tidal elevations are of comparable accuracy to those in optimally tuned forward tide models used in previous studies. The model captures $93 \%$ of the open-ocean sea-surface height variance of the eight largest tidal constituents, as recorded by a standard set of 102 pelagic tide gauges spread around the World Ocean. In order to minimize the impact of the wave drag on non-tidal motions, the model utilizes a running 25-h average to approximately separate tidal and non-tidal components of the near-bottom flow. In contrast to earlier high-resolution global baroclinic tide simulations, which utilized tidal forcing only, the simulation presented here has a horizontally non-uniform stratification, supported by the wind- and buoyancy forcing. The horizontally varying stratification affects the baroclinic tides in high latitudes to first order. The magnitude of the internal tide perturbations to sea surface elevation amplitude and phase in a large box surrounding Hawai'i is quite similar to that observed in satellite altimeter data, although the exact locations of peaks and troughs in the modeled perturbations differ from those in the observed perturbations.
\end{abstract}

(C) 2010 Elsevier Ltd. All rights reserved.

\section{Introduction}

This paper presents an early attempt to simultaneously resolve the oceanic general circulation, its associated mesoscale eddy field, and the barotropic and baroclinic tides, at high horizontal and vertical resolution, in a global model. A number of scientific and operational topics can be addressed in such a model-for instance, the interactions between tides and low-frequency motions, and the effect of eddies on the predictability of internal tides. We forgo some of these interesting scientific questions here, until more detailed and time-consuming analyses of our results are undertaken. The focus here is on the numerical techniques we have used to ensure an accurate barotropic tide without severely disrupting the eddying general circulation. As will be described below, it is far from trivial to ensure an accurate barotropic tide in forward global models, and the presence of non-tidal motions only increases the challenge. We also present a few preliminary results from our simulations. We present comparisons with observations from both satellite altimeters and tide gauges. These comparisons indicate that we have achieved some success in reproducing the observed

\footnotetext{
* Corresponding author.

E-mail address: barbic@fsu.edu (B.K. Arbic).
}

barotropic and baroclinic tide fields. We demonstrate the first-order effect of horizontally varying stratification on the global internal tides. Finally, we provide a few visual demonstrations of the co-existence of barotropic tides, baroclinic tides, the general circulation, and mesoscale eddies in the model.

In recent years, several groups have simulated the global oceanic general circulation in numerical models with horizontal grids that are fine enough to resolve (or at least permit) mesoscale eddies, the transient turbulent features which contain a substantial fraction of the oceanic kinetic energy. For instance, the Parallel Ocean Program (POP) model has been run globally at $1 / 10^{\circ}$ resolution (Maltrud and McClean, 2005), the Naval Research Laboratory Layered Ocean Model (NLOM) is run in ocean forecast mode with $1 / 32^{\circ}$ horizontal resolution (Shriver et al., 2007), the HYbrid Coordinate Ocean Model (HYCOM) is being developed as a $1 / 12.5^{\circ}$ resolution forecast model (Chassignet et al., 2007), the Ocean General Circulation Model for the Earth Simulator (OfES) has been run at 1/ $10^{\circ}$ resolution (Masumoto et al., 2004), and the Ocean Circulation and Climate Advanced Model (OCCAM) has achieved $1 / 12^{\circ}$ horizontal resolution (Lee et al., 2007). At the same time, in recent years, high-resolution global models of the baroclinic tides have begun to be run (Arbic et al., 2004 - hereafter, AGHS; Simmons et al., 2004 - hereafter, SHA; Hibiya et al., 2006; Simmons, 2008). 
In coastal models, it is common to model tides and non-tidal motions simultaneously. However, tides and non-tidal motions have almost always been simulated separately in global models. A few recent global simulations have included tides and non-tidal motions simultaneously (Schiller and Fiedler, 2007; T. Dobslaw, M. Müller, and M. Thomas, personal communication, 2008), but these studies are done with model horizontal grid spacings of order one degree, at which neither mesoscale eddies nor baroclinic tides are resolved. ${ }^{1}$ Here we merge two previously separate recent threads in the literature - high-resolution modelling of the global eddying general circulation, and high-resolution modelling of the global barotropic and baroclinic tides.

By combining these two threads we potentially improve the modelling of both types of motions, which affect each other in various ways. Interactions between mesoscale eddies and internal tides have the potential to transfer part of the coherent internal tide energy into incoherent signals, and to affect tidal energy budgets (Park and Watts, 2006; Rainville and Pinkel, 2006; Zaron et al., 2009; Chavanne et al., in press-a, in press-b). Park and Watts (2006) and Chavanne et al. (in press-b) show that the variations in stratification induced by mesoscale eddies, in addition to the scattering arising from eddy velocities, have important effects on internal tide propagation. A mixed tidal/non-tidal model is also more likely to properly account for the effects of the quadratic bottom boundary layer drag term. Currently, many ocean general circulation models insert an assumed tidal background flow, typically taken to be about $5 \mathrm{~cm} \mathrm{~s}^{-1}$, into the quadratic drag formulation (e.g. Willebrand et al., 2001). However, in the actual ocean tidal velocities vary from $\sim 1-2 \mathrm{~cm} \mathrm{~s}^{-1}$ in the abyss, to $\sim 50-100 \mathrm{~cm}$ $\mathrm{s}^{-1}$ in areas of large coastal tides. Thus an assumed tidal background flow of $5 \mathrm{~cm} \mathrm{~s}^{-1}$ is too strong in the abyss, and too weak in coastal areas. By actually resolving the (spatially inhomogeneous) tidal flows in a general circulation model, we take a step towards correcting this problem. The explicit resolution of tides may represent an important step towards more realistic representation of mixing in high-resolution models, and we are currently pursuing this avenue as well. Finally, the stratification in a mixed tidal/nontidal model can vary horizontally as in the actual ocean, since the wind- and buoyancy-forcing which supports this varying stratification is present. In contrast, the stratification in the earlier high-resolution global baroclinic tide simulations of AGHS and SHA was chosen to be horizontally uniform since these simulations did not include wind- and buoyancy-forcing.

The results presented here represent an important first step towards one of our long-term goals, to simultaneously resolve tides and non-tidal motions in global data-assimilative models with $1 /$ $25^{\circ}$ horizontal resolution. Because the goal is an operational model, accuracy of all the resolved motions is paramount. We therefore, desire to begin with forward tide models that are as accurate as possible. In recent years, it has been shown that achieving accurate surface elevations in forward global barotropic tide models requires the insertion of a parameterization of drag (and energy loss) due to the breaking of internal waves generated by tidal flow over rough topography (Jayne and St. Laurent, 2001; Carrere and Lyard, 2003; Egbert et al., 2004; AGHS; Lyard et al., 2006; Uehara et al., 2006; Griffiths and Peltier, 2008, 2009). These parameterizations are motivated by inferences from tide models constrained by satellite altimetry of the dissipation of tidal energy in mid-ocean areas of rough topography (Egbert and Ray, 2000), as well as in-situ evidence of elevated dissipation levels in such areas (e.g. Polzin et al., 1997). The subtleties of applying a parameterized topographic wave drag in models which resolve the generation of low-mode baroclinic

\footnotetext{
1 To be more precise about the Schiller and Fiedler (2007) simulation, their resolution was high in an area around Australia, but the telescoping grid they used led to low resolutions over most of the global ocean.
}

tides, and in models which resolve non-tidal as well as tidal motions, will be discussed in the next section. A comparison and discussion of the accuracies of the barotropic tides in the baroclinic simulations of AGHS and SHA will prove to be instructive with regard to handling topographic wave drag in the new HYCOM simulations.

\section{Inclusion of parameterized topographic wave drag}

\subsection{Need for parameterized wave drag in baroclinic tide models}

In barotropic tide models, none of the internal waves generated by flow over rough topography are resolved, and all of this wave activity must be parameterized. In baroclinic tide models, the situation is more complicated and interesting. The resolved generation of low-mode internal tides means that the barotropic tide will be losing energy to the baroclinic tide in baroclinic models. Indeed, the computation of this energy conversion was a central goal of SHA, which built upon the baroclinic tide simulations performed for AGHS. Both studies were done with HIM, the Hallberg Isopycnal Model (Hallberg and Rhines, 1996). Since in baroclinic tide models energy is lost from the barotropic mode, it is tempting to view parameterized topographic wave drag as redundant. Indeed, the main baroclinic simulation of SHA did not retain the parameterized topographic wave drag used in the main AGHS baroclinic simulations. We now examine the consequences of these different choices made in AGHS and SHA.

Table 1 shows the globally integrated available potential energy (APE) at the sea surface, and the globally integrated barotropic kinetic energy (KE), both computed via standard formulae which can be looked up in for instance AGHS, in (1) the satellite altimeter-constrained barotropic solutions of Egbert and Ray (2003), (2) the main baroclinic simulation of AGHS (see their Fig. 11), which utilized parameterized topographic wave drag optimally tuned to minimize sea surface elevation errors with respect to satellite altimetry, (3) a baroclinic simulation of AGHS which did not utilize parameterized topographic wave drag and which also used only the scalar approximation (e.g. Ray, 1998) for the self-attraction and loading term (in other words, run under conditions similar to the main baroclinic simulation of SHA), (4) the main baroclinic simulation of SHA, and (5) a baroclinic simulation of SHA briefly mentioned in their appendix, in which, inspired by Fig. 2 of AGHS, an unrealistically large value of $c_{d}$ (100 times the normal value) was utilized as a proxy for topographic wave drag. The globally- and temporally-averaged root-mean-square (RMS) elevation errors of the forward models with respect to GOT99 (Ray, 1999), a highly accurate altimetryconstrained tide model, are also shown. The errors are computed over waters deeper than $1000 \mathrm{~m}$ and over latitudes covered by the TOPEX/POSEIDON altimeter (equatorward of $66^{\circ}$ ). ${ }^{2}$ Finally, the percentage of the GOT99 open-ocean sea surface height (SSH) variance captured by the models is shown. AGHS may be consulted for details of how the errors and percent variance captured are calculated. In the main baroclinic simulation of AGHS, the surface APE and barotropic KE are both quite close to the Egbert and Ray values, and as a result the surface elevation error is reasonably small. Note also that the barotropic energies and elevation errors in this optimally tuned AGHS baroclinic simulation are barely different from those in the optimally tuned one-layer simulation of AGHS (not shown). On the other hand, in the AGHS baroclinic simulation run without any parameterized topographic wave drag, the surface $\mathrm{APE}$ and barotropic KE are both about twice as large as the ob-

\footnotetext{
2 To be precise, the errors in the SHA results were computed over the latitude range $66^{\circ} \mathrm{S}$ to $64^{\circ} \mathrm{N}$, in order to avoid the complex tripolar grid utilized in the high latitudes of that study in the error computations.
} 
Table 1

Energies and elevation errors of earlier forward global baroclinic tide models, compared to results from an altimetry-constrained tide model. Globally integrated surface available potential energy (APE) and barotropic kinetic energy (KE) of $M_{2}$ are computed from (1) Table 1 of Egbert and Ray (2003 - ER2003 below-based on an altimetry-constrained barotropic model), (2) main baroclinic simulation of AGHS (see their Fig. 11), (3) AGHS baroclinic simulation without parameterized topographic wave drag and with only a scalar approximation for self-attraction and loading (SAL); i.e. conditions like those in the main baroclinic simulation of SHA, (4) main SHA baroclinic simulation (see their Fig. 8), (5) a baroclinic simulation in the appendix of SHA, with an artificially large $c_{d}$ value of 0.3 standing in as a proxy for parameterized topographic wave drag. Units of energies are $10^{17} \mathrm{~J}$. Globally averaged sea-surface elevation discrepancies $(\mathrm{cm})$ with respect to GOT99, computed over latitudes equatorward of $66^{\circ}$ and waters deeper than $1000 \mathrm{~m}$, are also given. Numbers in parentheses indicate percent of altimeter-measured open-ocean sea surface elevation variance captured by the models.

\begin{tabular}{llll}
\hline Model & $\begin{array}{l}\text { Surface } \\
\text { APE }\end{array}$ & $\begin{array}{l}\text { Barotropic } \\
\text { KE }\end{array}$ & $\begin{array}{l}\text { RMS elevation } \\
\text { error }\end{array}$ \\
\hline $\begin{array}{l}\text { ER2003 } \\
\begin{array}{c}\text { AGHS main baroclinic } \\
\text { simulation }\end{array}\end{array}$ & 1.34 & 1.78 & - \\
$\begin{array}{c}\text { AGHS, no parameterized } \\
\text { drag, scalar SAL }\end{array}$ & 3.18 & 3.73 & $7.37(92.4)$ \\
$\begin{array}{c}\text { SHA main baroclinic } \\
\text { simulation }\end{array}$ & 4.37 & 5.09 & $17.14(58.8)$ \\
$\begin{array}{c}\text { SHA, large } c_{d} \text { as proxy } \\
\text { for wave drag }\end{array}$ & 1.66 & 2.03 & $23.35(23.5)$ \\
\hline
\end{tabular}

served values. As a consequence the elevation discrepancy with respect to GOT99 is much larger, and the percentage of SSH variance captured is much lower. Consistent with this result, both the potential and kinetic energies of the main SHA baroclinic simulation are also larger, by factors of about 3, than those in the accurate satellite-constrained models, and the high elevation error and low percent variance captured reflect this mismatch. ${ }^{3}$ The large $c_{d}$ simulation mentioned in the appendix of SHA performs much better with respect to the observations (and sees a factor of 2.4 drop in the conversion of barotropic to low-mode baroclinic energy), demonstrating that even artificial frictions can lead to accurate modeled barotropic tides as long as they remove energy at approximately the correct rate.

In the current study we have also found that the barotropic tide is extremely inaccurate if parameterized topographic wave drag is not included. As in AGHS, we choose to have the topographic wave drag in HYCOM acting on the near-bottom flow (in the HYCOM multi-layer simulations we define "near-bottom" flow as flow averaged over the bottom $500 \mathrm{~m}$ ). AGHS argued that a conversion of energy from barotropic to baroclinic tides in baroclinic models does not represent a loss of energy in the total (barotropic plus baroclinic) system, since the models do not resolve the breaking of baroclinic tides occuring in the actual ocean. Parameterized topographic wave drag acting on the near-bottom flow, unlike modal conversion, drains total energy from the model. The near-bottom flow is a function of both barotropic and baroclinic tides, the latter contributing less when the stratification is surface-intensified, as is typical in the ocean. If we assume that wave breaking takes place mostly in the deep ocean, just above rough topography, and involves mostly high vertical modes, then the parameterization represents the breaking of high modes near the bottom, which is not resolved in present-day global baroclinic tide models. It remains to be seen whether this is the best representation of what actually happens in nature (some of the tidal energy loss in the actual ocean may

\footnotetext{
${ }^{3}$ Consistent with these results of AGHS and SHA, a new simulation of baroclinic tides performed with $\sim 50$ z-levels in the vertical direction and $1 / 4^{\circ}$ horizontal resolution shows excessively large barotropic tides in the absence of parameterized topographic wave drag (Andrew Coward, Ariane Koch-Larrouy, Gurvan Medec, Adrian New, George Nurser, and David Smeed, personal communication, 2009).
}

be due to high vertical mode breaking in the upper ocean), but it is clearly true empirically that it results in far superior barotropic tides than those in simulations which do not utilize parameterized topographic wave drag. It is clear that any forward global tide model that aspires to be the starting point for an operational model must include a parameterized topographic wave drag, or some other way of removing total energy from the model. ${ }^{4}$

The need for a parameterized topographic wave drag to achieve accurate barotropic tides is linked with the horizontal and vertical resolutions available in the model; if the breaking of high vertical mode waves and consequent energy loss could be properly resolved, then parameterized topographic wave drag would not be needed. The HYCOM simulations presented here utilize horizontal and vertical resolutions that are state-of-the-art, in accordance with the largest computers presently available. Prompted by the suggestion of one of the reviewers (Sonya Legg), we briefly discuss here the limitations of these resolutions. From Fig. 11 of SHA, we take the wavelength of the first baroclinic mode $M_{2}$ internal tide to be about $100 \mathrm{~km}$ in mid-latitudes. A widely used rule of thumb holds that eight gridpoints per wavelength are required to properly resolve waves in a model. The $1 / 12.5^{\circ}$ horizontal resolution in our simulations translates to about $9 \mathrm{~km}$ grid spacing. Therefore, the mode one internal tides are well-resolved in our simulations. However, since the wavelengths drop off approximately as $1 / n$, where $n$ is the vertical mode number, then the mode two internal wave has a wavelength of about $50 \mathrm{~km}$, meaning there are less than 8 gridpoints per wavelength. By the time we reach vertical mode numbers of about ten or so, there will be only one gridpoint per wavelength. All of this suggests that vertical mode numbers beyond about 10 are probably not resolved at all in the simulations presented here, and vertical mode numbers beyond one or two are probably not well-resolved. Thus horizontal resolution limitations are in part responsible for the fact that parameterized topographic wave drag is still required to achieve accurate barotropic tides in baroclinic tide models.

To end this subsection we note that despite the fact that the low-mode baroclinic tides have a weak signature at the bottom, it is evident that insertion of parameterized topographic wave drag into a baroclinic tide model affects the propagation distances of the low-mode internal tides. Contrast, for instance, the shorter propagation distances of the low-mode internal tide beams from their source regions shown in Fig. 11 of AGHS with the longer distances seen in Fig. 8 of SHA.

\subsection{Adaptation of parameterized wave drag used in previous studies}

We utilize an adaptation of the topographic wave drag scheme described in the appendix of AGHS, which is based on the scheme outlined in Garner (2005). A multiplicative factor was included in the scheme and tuned to minimize the globally averaged deepocean RMS elevation discrepancy between the forward model and GOT99. AGHS found that the optimal multiplicative factor, for $1 / 2^{\circ}$ simulations with wave drag acting only in waters deeper than $1000 \mathrm{~m}$, was about 7 . AGHS suggested that the multiplicative factor may compensate for the small scales that are absent in the roughness of present-day topographic datasets (e.g. Smith and Sandwell, 1997). This suggestion will shortly be tested, in tide model runs which utilize global grids of statistical roughness produced by Goff and Arbic (2010). These grids utilize relationships between geophysical properties such as seafloor spreading rate and abyssal hill statistics to produce synthetic topographies. The

\footnotetext{
${ }^{4}$ Along with several collaborators, we are exploring the possibility of removing energy directly from the resolved vertical shear.
} 
Tidal Drag E-Folding Time (days)
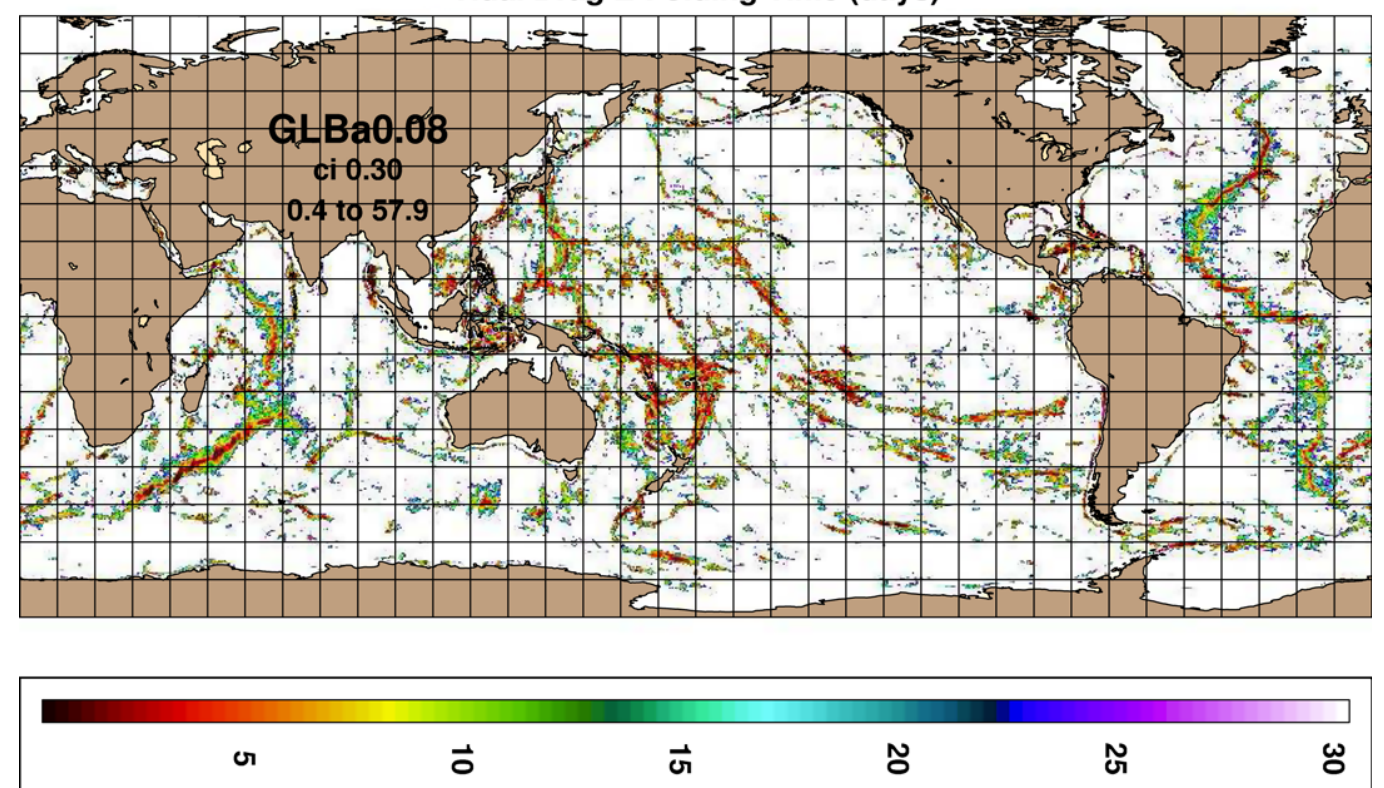

Fig. 1. E-folding time (days) for parameterized topographic wave drag with drgscl $=1$. The majority of the white areas have no wave drag at all.

statistical roughness grids can be overlaid on the Smith and Sandwell (1997) dataset to create global bathymetries with the right statistical texture of the seafloor, though they are not deterministically correct. We can use the new rougher topography as an input to our drag scheme to determine if smaller multiplicative factors can then be used. It is important to note that while these exercises will test the robustness of the underlying wave drag scheme used in AGHS (since a multiplicative factor of 7 should not be necessary for a correct scheme that utilizes a topography of adequate resolution), they will not greatly affect the total drag required by the model to bring about accurate tides. As noted by AGHS, the globally averaged strength of wave drag used in AGHS and in Jayne and St. Laurent (2001), which utilized completely different schemes and tunable parameters, was virtually identical. As a practical matter, a certain amount of drag is needed to obtain accurate barotropic tides. Whether the underlying theory can come to this correct amount of drag without a tunable parameter such as our multiplicative factor is an important question, but one of limited practical consequence.

For the sake of simplicity, here we reduce the AGHS tensor scheme to a scalar scheme, utilizing energy considerations. We compute from $1 / 8^{\circ}$ runs of the AGHS model the quantity

$r=\frac{\left\langle\left.\frac{d \overrightarrow{\mathbf{u}}}{d t}\right|_{\text {topodrag }} \cdot \overrightarrow{\mathbf{u}}\right\rangle}{\langle\overrightarrow{\mathbf{u}} \cdot \overrightarrow{\mathbf{u}}\rangle}$,

where angle brackets denote time-averaging, $\overrightarrow{\mathbf{u}}$ is the velocity vector, and $\left.\frac{d \overrightarrow{\mathbf{u}}}{d t}\right|_{\text {topodrag }}$ is the term in the momentum equation of the (barotropic) AGHS model arising from the full tensor form of the topographic wave drag. We use the resulting map of $r$ in the HYCOM simulations. Note that $r$ is a linear drag coefficient, with $1 / r$ as its efolding time scale. Here we set the values of $r$ to zero in regions shallower than $500 \mathrm{~m}$ and where it is small, i.e. where the e-folding time is greater than 30 days, which together account for $73 \%$ of the area of the World Ocean. We also clip the value of $r$ so that its minimum e-folding time is $9 \mathrm{~h}$. Both of these actions limit the impact of the wave drag on non-tidal motions (see next section). Fig. 1 shows maps of $1 / r$ values obtained after all of these changes have been implemented. The drag is concentrated over well-known areas of rough topography such as the Mid-Atlantic Ridge, Southwest Indian Ridge, etc. In the $1 / 12.5^{\circ}$ simulations we will be presenting shortly, we found that a multiplicative factor of 6 yielded accurate tides, similar to the optimal multiplicative factor of about 7 found by AGHS. ${ }^{5}$ Hence, the e-folding time of the applied drag is $1.5 \mathrm{~h}$ to six days with no drag over $73 \%$ of the worlds oceans.

\subsection{Utilizing topographic wave drag in the presence of non-tidal motions}

On the relatively fast timescales of internal gravity waves, lowfrequency motions such as mesoscale eddies and strong currents (i.e. the Gulf Stream, Antarctic Circumpolar Current, etc.) can be regarded as steady. The generation of internal gravity waves (lee waves) by steady flows over rough topography is a classic problem in geophysical fluid dynamics (e.g. Gill, 1982). Tidal motions are oscillatory, not steady, and the work of Bell (1975) shows that the wave drag resulting from oscillatory flow over rough topography differs from the wave drag resulting from steady flow. In the future we may wish to include a parameterized wave drag for the non-tidal (steady, in this context) flow over rough topography in HYCOM. Indeed, some recent papers have argued that this mechanism represents a substantial energy loss for low-frequency motions (Naveira-Garabato et al., 2004; Marshall and NaveiraGarabato, 2008; Nikurashin, 2008). For now, however, we wish to have the wave drag acting only on the tidal part of the flow. This presents a challenge: how is the model to know the partition of tidal versus non-tidal near-bottom flows? In order to accomplish this separation, at least roughly, we utilize running 25 -h averages before applying the topographic wave drag to the near-bottom flow. The details of this scheme are discussed next.

\footnotetext{
${ }^{5}$ Arbic et al. (2008) found that when the HIM tide model was run at higher resolution $\left(1 / 8^{\circ}\right)$ and the topographic wave drag acted in shallow as well as deep waters, accurate tides could be obtained with a multiplicative factor as small as 3 . The higher multiplicative factor needed in high-resolution HYCOM may be due in part to the clipping described earlier, and to the fact that the wave drag does not operate in shallow waters. The optimal multiplicative factor apparently varies by a factor of about 2, depending on model resolution, cutoff depth for utilizing the wave drag, and other factors.
} 
2.4. Separation of tidal from non-tidal near-bottom flows in wave drag scheme

The topographic wave drag is nominally applied to the tidal flow only and acts on the bottom $500 \mathrm{~m}$ of the water column (recall that the wave drag is zero in waters shallower than $500 \mathrm{~m}$ ). To filter out the tides we first form the average of 25 hourly samples of the velocity over the bottom $500 \mathrm{~m}$ lagged in time (i.e. from the previous $25 \mathrm{~h}$ ). Since the 25 -h period is very close to twice that of the dominant tidal constituent $M_{2}$, most of the tidal motions are filtered out of these averages. This is the detided bottom flow $\overrightarrow{\overrightarrow{\mathbf{u}}_{b}}$ which is used as a correction to standard implicit linear friction over the bottom $500 \mathrm{~m}$ of the water column:

$\overrightarrow{\mathbf{u}}^{t+\Delta t}=\overrightarrow{\mathbf{u}}^{t-\Delta t}-2 \Delta t \sigma\left(\overrightarrow{\mathbf{u}}^{t+\Delta t}-\overline{\overrightarrow{\mathbf{u}}_{b}}\right)$

Here, $\sigma$ is the linear drag coefficient which in this case is $6 r$. The friction is implicit for stability, given the large drag coefficient. A 25-h average is not an exact tidal filter, and lagging it in time may introduce aliasing, but there are limits on what is practical in a running ocean model. In an 8-constituent tides only test case, adding the 25-h filter had minimal effect on the accuracy of the tides. This issue is further explored in Section 5.3. It is important to reiterate that, in the governing equations of the model, the separation of tidal from non-tidal flows with a 25 -h filter is done only during the application of the topographic wave drag to the bottom flow. Tidal and low-frequency flows can still interact with each other through various terms in the model equations-advection, nonlinearities in the mass conservation equation, and quadratic bottom boundary layer drag, for example. Tidal and non-tidal flows are not separated from each other in these other cases in our governing model equations.

\section{Implementation of self-attraction and loading}

Hendershott (1972) showed that global numerical tide models must account for self-gravitation of the ocean tide, solid earth deformation due to the load of the ocean tide, and perturbations to the gravitational potential due to the self-gravitation of the solid earth thus deformed. Collectively, these terms are known as the self-attraction and loading (SAL) term. A complete treatment of the SAL term requires computing a spherical harmonic decomposition of the ocean tide. This is not computationally feasible to do in the model as it runs, and instead is often done offline. An iterative procedure appears to be necessary to achieve numerical convergence (e.g. Egbert et al., 2004, AGHS). In the model runs presented here, as was done in SHA, we use the scalar approximation, in which the SAL term is approximated as a constant $\beta$ times the sea surface elevation field $\eta$. The scalar approximation is less accurate than the proper spherical harmonic treatment, but is far more computationally expedient. In tests with HYCOM forced only by tides, we found that the optimal value of this constant in terms of minimizing the globally averaged RMS sea surface elevation discrepancy with GOT99 is 0.06 . Since the load numbers used in proper calculations of the SAL term depend on the degree of spherical harmonic, this value of $\beta$, which was determined for the barotropic tides, is not valid for smaller scale features such as mesoscale eddies and internal tides.

As pointed out by Hendershott (1972), the SAL term should apply to non-tidal as well as tidal flows. However, as noted above, the value of the SAL scalar $\beta$ we use is not appropriate for mesoscale eddies. We choose to apply the scalar SAL approximation to the non-steric SSH, which is dominated by barotropic tides (see Fig. 8). The non-steric height is the difference between the SSH and the steric SSH. The steric SSH anomaly is taken to be the change in SSH due to the difference between the instantaneous vertical potential density profile and a multi-year model mean profile, and the total steric SSH is taken to be this anomaly plus the corresponding multi-year model mean $\mathrm{SSH}$. This procedure ensures that SAL is applied to the barotropic tides at the same time that it is not improperly applied (i.e. with an inappropriate $\beta$ value) to mesoscale eddies. As with topographic wave drag, the problem of applying SAL to mixed tidal/general circulation runs deserves careful consideration, and we will continue to explore different options for the SAL term in future work.

\section{Other details of the HYCOM simulations}

HYCOM is a community ocean model (http://oceanmodeling.rsmas.miami.edu/hycom/) and uses a generalized (hybrid isopycnal/terrain - following $(\sigma) / z$-level) vertical coordinate (Bleck, 2002). Typically, the model includes isopycnal coordinates in the stratified ocean but uses the layered continuity equation to make a dynamically smooth transition to $z$-levels (fixed-depth coordinates) in the unstratified surface mixed layer or to $\sigma$-levels (terrain-following coordinates) in shallow water. The optimal coordinate is chosen every time step using a hybrid coordinate generator. In this way, the model automatically generates the lighter isopycnal layers needed for the pycnocline during summer, while the same layers may define $z$-levels during winter.

In simulations done for this paper HYCOM uses the K-Profile Parameterization (KPP; Large et al., 1994) for full-column mixing, so interior diapycnal mixing is from KPPs background mixing terms. The background/internal wave viscosity is set to $1 \mathrm{~cm}^{2} \mathrm{~s}^{-1}$ and the diffusivity to $0.1 \mathrm{~cm}^{2} \mathrm{~s}^{-1}$.

The model spans the entire globe north of $78.6^{\circ} \mathrm{S}$, with a Mercator grid from $66^{\circ} \mathrm{S}$ to $47^{\circ} \mathrm{N}$, at a resolution of $0.08^{\circ} \cos ($ lat) $\times 0.08^{\circ}$ (latitude $\times$ longitude), and a bipolar Arctic patch north of $47^{\circ} \mathrm{N}$, i.e. a tripole grid (Murray, 1996). The average zonal (longitudinal) resolution for this $1 / 12.5^{\circ}$ global grid varies from $\approx 9 \mathrm{~km}$ at the equator to $\approx 7 \mathrm{~km}$ at mid-latitudes (e.g. at $40^{\circ} \mathrm{N}$ ) and $\approx 3.5 \mathrm{~km}$ at the north pole. The meridional (latitudinal) grid resolution is halved in the Antarctic for computational efficiency. The total number of gridpoints for each vertical level in the simulation is 3297 (nominally, the north-south direction) by 4500 (nominally, the east-west direction). The model's land-sea boundary is at the $10-\mathrm{m}$ isobath and it potentially uses a terrain-following vertical coordinate in depths shallower than $140 \mathrm{~m}$. The bottom topography was constructed from the NRL Digital Bathymetry Data Base (DBDB2), which has a resolution of 2-min and is available online at http://www7320.nrlssc.navy.mil/DBDB2_WWW/. Numerous hand-edits have been performed to improve coastlines and sill depths in key straits and passages.

There are 32 hybrid layers in the vertical direction in the model. The target density values for the isopycnals and the decreasing change in density with depth between isopycnal coordinate surfaces are based on the $1 / 4^{\circ}$ Generalized Digital Environmental Model (GDEM) climatology (NAVOCEANO, 2003; Carnes, 2009). We take the GDEM z-level climatology to create an "isopycnal" climatology to initialize HYCOM based on the target densities. The density difference values were chosen, so that the layers tend to become thicker with increasing depth, with the lowest abyssal layer being the thickest. The layer thicknesses are not the same everywhere, but vary spatially (see Fig. 10). Upon initialization, a given gridpoint may be in any of the three coordinate types (isopycnal, z-level, or terrain following) and this may change with depth as well. The hybrid coordinate generator favors isopycnal layers. The minimum thickness of each layer is not zero, as it would be for an outcropped layer in a purely isopycnal model, but rather a fixed value per layer that implicitly creates the z-level coordinates. So, isopycnal layers effectively outcrop into the z-levels formed by 
the layers above rather than at the surface. The minimum thickness of the top layer in deep water is $3 \mathrm{~m}$, and this minimum increases $1.18 \times$ per layer up to a maximum of $450 \mathrm{~m}$, and target densities are chosen such that at least the top four layers are always in z-level coordinates.

The initial model spin-up run was initialized from the January GDEM climatology and forced by years 1979-2002 from the European Centre for Medium-Range Weather Forecasts (ECMWF) 40year Re-Analyses (ERA-40) (Kållberg et al., 2004) averaged to form a climatological monthly mean atmospheric forcing. The wind speeds were scaled to be consistent with QuikSCAT observations (Kara et al., 2009). The 6-hourly sub-monthly wind anomalies from the $0.5^{\circ}$ Fleet Numerical Meteorology and Oceanography Center (FNMOC) Navy Operational Global Atmospheric Prediction System (NOGAPS; Rosmond et al., 2002) over year 2003 were added to the 12 monthly averages to obtain realistic mixed layer depths and to allow continuation with 3-hourly or 6-hourly interannual winds data sets.

\section{Results}

\subsection{Description of simulations and sampling issues}

The results here are taken from five different simulations of HYCOM, designated by 9.7, 13.1, 14.0, 14.1, and 14.2 (Table 2). HYCOM 13.1 ("Tideonly") is a simulation with a horizontally uniform two layer stratification and only tidal forcing, performed so that comparison with wind-, buoyancy-, and tidally forced simulations will reveal effects of horizontally non-uniform stratification on internal tides. HYCOM 9.7 serves as our "Control" experiment, with wind- and buoyancy-forcing but without any tidal forcing. It started from the end of the spin-up simulation and was run from 2003 through mid-2008 using 3-hourly FNMOC NOGAPS atmospheric forcing with wind speeds scaled to be consistent with QuikSCAT observations. HYCOM 14.0 ("M2tide") was a test experiment, performed for just two months starting in July 2003 from HYCOM 9.7 (Control). HYCOM 14.0 (M2tide) included $M_{2}$ tidal forcing as well as wind- and buoyancy-forcing. Encouraged by the results of 14.0 (M2tide), we then proceeded to 14.1 ("Alltides"), an experiment again starting from 9.7 (Control) in July 2003 but covering 5 calendar years after allowance for spinup (2004-2008). HYCOM 14.1 (Alltides) included tidal forcing for $M_{2}, S_{2}, N_{2}$, and $K_{2}$ (the four largest semidiurnal constituents), and

Table 2

Simulation number, shorthand name, and characteristics of HYCOM simulations described in this paper.

\begin{tabular}{|c|c|c|}
\hline $\begin{array}{l}\text { Simulation } \\
\text { number }\end{array}$ & $\begin{array}{l}\text { Shorthand } \\
\text { name }\end{array}$ & Characteristics \\
\hline \multirow[t]{3}{*}{9.7} & Control & 32-layers \\
\hline & & Wind- and buoyancy forcing \\
\hline & & No tidal forcing or topographic wave drag \\
\hline \multirow[t]{3}{*}{13.1} & Tideonly & 2-layers \\
\hline & & No wind- and buoyancy forcing \\
\hline & & $M_{2}$ tidal forcing and topographic wave drag \\
\hline \multirow[t]{4}{*}{14.0} & M2tide & 32-layers \\
\hline & & Wind- and buoyancy forcing \\
\hline & & $M_{2}$ tidal forcing and topographic wave drag \\
\hline & & Short duration (two months) \\
\hline \multirow[t]{3}{*}{14.1} & Alltides & 32-layers \\
\hline & & Wind- and buoyancy forcing \\
\hline & & $\begin{array}{l}\text { Eight-constituent tidal forcing and } \\
\text { topographic wave drag }\end{array}$ \\
\hline \multirow[t]{4}{*}{14.2} & 3Doutput & 32-layers \\
\hline & & Wind- and buoyancy forcing \\
\hline & & $\begin{array}{l}\text { Eight-constituent tidal forcing and } \\
\text { topographic wave drag }\end{array}$ \\
\hline & & $\begin{array}{l}\text { Full global 3D output saved hourly, for one } \\
\text { month }\end{array}$ \\
\hline
\end{tabular}

$K_{1}, O_{1}, P_{1}$, and $Q_{1}$ (the four largest diurnal constituents), as well as the same wind- and buoyancy-forcing used in 9.7 (Control).

In many applications involving tides, it is desirable to store information hourly. However, at the vertical and horizontal resolutions utilized here, it is impractical to save full global three-dimensional output hourly for all five years of the 14.1 simulation. We did save daily 25-h averages of three-dimensional 14.1 (Alltides) output. For the full five-year duration of 14.1 (Alltides), we saved global hourly output of SSH, and other surface fields. We also saved hourly full three-dimensional output, over the last three years of the run, in a few domains of great interest for the study of internal tides, such as Hawai'i, the Indonesian Archipelago, and others. Finally, simulation 14.2 ("3Doutput") is a twin of 14.1 (Alltides) for May 2004 but saves full three-dimensional model output hourly, over the entire globe.

The combined size of the stored output of HYCOM 14.1 (Alltides) is 68 terabytes (TB), and the single month in 14.2 (3Doutput) accounts for another $3 \mathrm{~TB}$. This is an enormous amount of material to analyze, and we have just begun to go through our results. Thus far a harmonic analysis of 14.1 (Alltides), commonly used to separate the contributions of the various tidal constituents, has been performed at only a limited number of locations, the 102 pelagic tide gauges of Shum et al. (1997). The harmonic analysis is used to determine the RMS surface elevation errors of the eight constituents in 14.1 (Alltides) with respect to the tide gauge data. Harmonic analysis on every gridpoint in such a large model is a very time-consuming endeavor. For this reason, we defer some of the analyses we wish to pursue on 14.1 (Alltides) to later papers. In this paper, we will show (1) results from the harmonic analysis of 14.1 (Alltides) at the tide-gauge stations, (2) other results from 14.1 (Alltides) which do not require a time-consuming harmonic analysis, and (3) some results from harmonic analysis of $M_{2}$ in one day of output (taken from the second month, to allow for spinup) from experiment 14.0 (M2tide). These latter results are possible because 14.0 (M2tide) does not contain any other tidal constituents. However, they should be regarded as preliminary because the internal tide is not necessarily stationary, so that one day of output may not be sufficient for a rigorous analysis of the internal tides.

\subsection{RMS surface elevation errors}

Table 3 shows the RMS time-averaged elevation signals of the eight largest consituents averaged over the 102 pelagic tide gauges, the elevation errors of year 2004 from HYCOM 14.1 (Alltides) with respect to the tide gauge records of these eight constituents, and the percent of the tide gauge sea surface elevation variance of these constituents captured by the model. AGHS may be consulted for details on how such calculations are performed. We also analyzed years 2003 (last 152 days) and 2006, and came up with virtually

Table 3

Time and station-averaged sea-surface height (SSH) signals at the set of 102 pelagic tide gauges used in Shum et al. (1997), and sea-surface elevation errors of year 2004 of our HYCOM 14.1 eight-constituent forward simulation (Alltides) with respect to the gauges. Numbers in parentheses denote percentage of SSH variance at the gauges captured by HYCOM. RSS denotes root-sum-square computed over all eight constituents.

\begin{tabular}{lcc}
\hline Constituent & Signal $(\mathrm{cm})$ & HYCOM 14.1 error $(\mathrm{cm})$ \\
\hline $\mathrm{Q}_{1}$ & 1.62 & $0.68(82.1)$ \\
$\mathrm{O}_{1}$ & 7.76 & $2.48(89.7)$ \\
$\mathrm{P}_{1}$ & 3.62 & $0.79(95.2)$ \\
$\mathrm{K}_{1}$ & 11.26 & $2.48(95.1)$ \\
$\mathrm{N}_{2}$ & 6.86 & $1.40(95.9)$ \\
$\mathrm{M}_{2}$ & 33.22 & $8.26(93.8)$ \\
$\mathrm{S}_{2}$ & 12.62 & $5.17(83.2)$ \\
$\mathrm{K}_{2}$ & 3.43 & $1.65(76.9)$ \\
$\mathrm{RSS}$ & 39.04 & $10.63(92.6)$ \\
\hline
\end{tabular}


identical elevation errors. The overall percent variance captured, $92.6 \%$, is slightly lower than that captured in the optimally tuned two-layer simulations of AGHS. The higher horizontal resolution used here should improve the solutions (Egbert et al., 2004; Arbic et al., 2008). However, in the latter models the full spherical harmonic computation of SAL was utilized, whereas here we have used only the scalar approximation. We conclude that for our first attempt at a mixed wind-plus-tides simulation the errors are reasonably small. Based on the experience in the literature we believe these errors will reduce with a more rigorous treatment of SAL, and with the introduction of data assimilation.

\subsection{Near-bottom speeds and SSH variability of non-tidal motions}

Because our parameterized topographic wave drag scheme acts on near-bottom flows, and because the 25-h filter we utilize along with the wave drag is an imperfect discriminator of tidal versus non-tidal flows, it is important to check that non-tidal near-bottom flows are not strongly affected with the addition of tides and topographic wave drag. Fig. 2a is a map of the mean kinetic energy $50 \mathrm{~m}$ above the bottom for HYCOM 9.7 (Control), averaged over 2006. Fig. $2 \mathrm{~b}$ displays the mean kinetic energy $50 \mathrm{~m}$ above the bottom for non-tidal flows in 14.1 (i.e. based on 25-h averaged daily cur- rents from Alltides), also for 2006. The two figures were not computed in exactly the same way, since in Fig. 2a the non-tidal flows (i.e. the total flows) were saved as daily snapshots whereas in Fig. $2 \mathrm{~b}$ the non-tidal flows were saved as 25 -h averages. However, as shown in Arbic et al. (2009), in present-day high-resolution models the non-tidal flows seem to be relatively unaffected by subsampling on scales of about a day. Comparison of the two figures, both of which mask out regions shallower than $1000 \mathrm{~m}$, demonstrates that on the whole, adding tides and parameterized topographic wave drag to the model does not reduce the non-tidal near-bottom flow. Indeed, in many regions it appears that the nontidal motions are on the contrary stronger in the tidally-forced case with topographic drag (14.1; Alltides) than they are in the non-tidal case (9.7; Control). We speculate that this may be because, as noted in Section 1, in the tidal simulation quadratic bottom boundary layer drag in the deep ocean is effectively weaker than it is in the non-tidal simulation. Another possibility is that some contribution from tidal flow is still present in the 25-h averages from 14.1 (Alltides), which would tend to increase mean kinetic energy. However, a test of the eight-constituent AGHS run shows that this effect is likely to contribute a maximum of $7 \mathrm{~cm}^{2} \mathrm{~s}^{-2}$ to the lowfrequency kinetic energy in waters deeper than $1000 \mathrm{~m}$. Larger differences than this are seen in the comparison of Fig. $2 \mathrm{a}$ and $\mathrm{b}$.

a

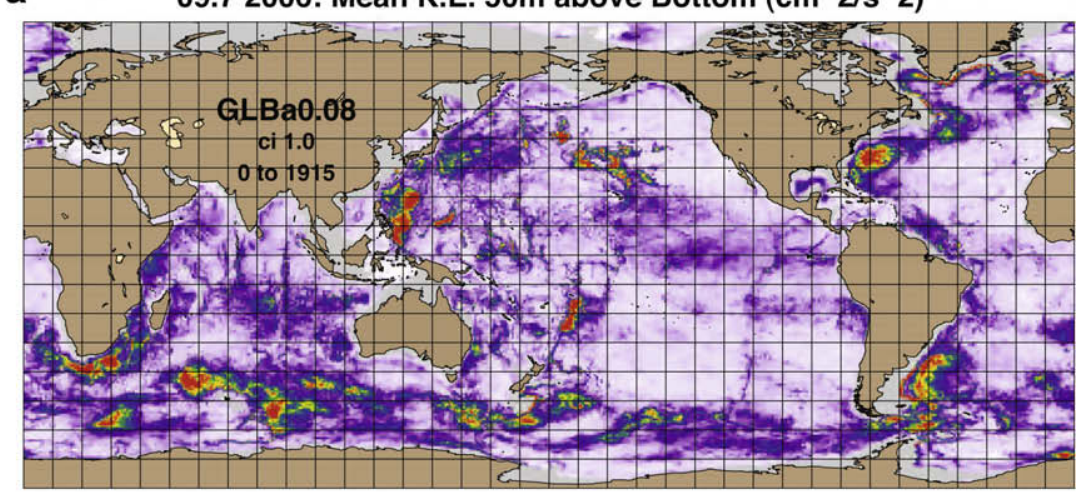

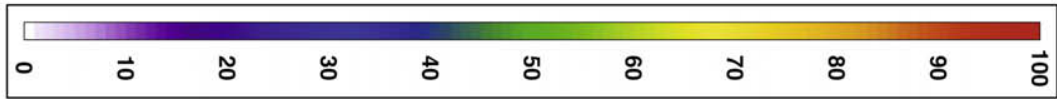

b

14.1 2006: Mean K.E. $50 \mathrm{~m}$ above Bottom $\left(\mathrm{cm}^{\wedge} 2 / \mathrm{s}^{\wedge} 2\right)$
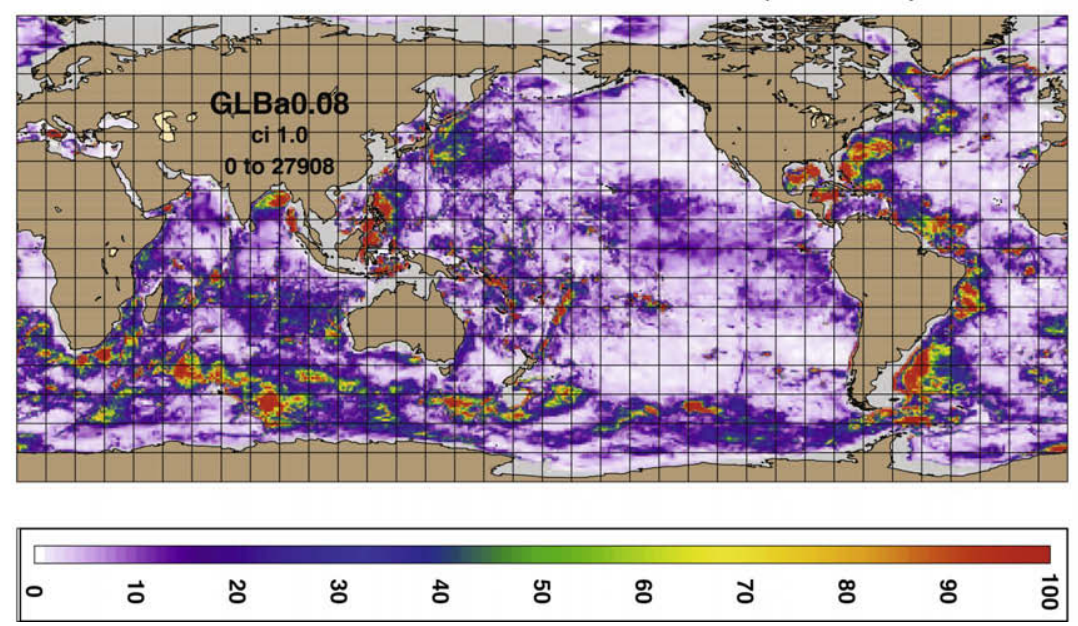

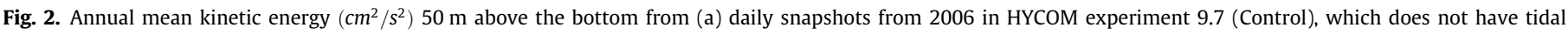

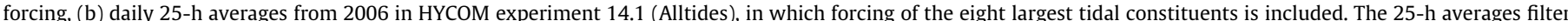

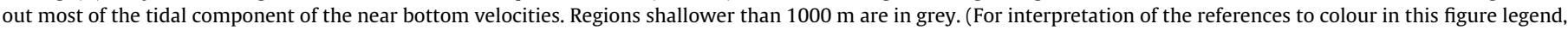
the reader is referred to the web version of this article.) 
Some of the regions of large mean kinetic energy are also where the topographic wave drag is very strong (e.g. the Gulf of Mexico and some of the Indonesian Seas). Our 25-h averaging scheme for applying this drag only to the tidal component appears to induce artificially large mean velocities in some locations. We are exploring alternative approaches for implementing topographic wave drag in subsequent simulations with tides and eddies.

Another check on the impact of including tides and parameterized wave drag on low-frequency flows is given in Fig. 3. Fig. 3 shows the RMS low-frequency SSH variability over 20042007 from HYCOM 9.7 (Control) and HYCOM 14.1 (Alltides). The fields from the two simulations are remarkably similar, indicating that the low-frequency SSH variability is not greatly affected by the addition of tides and topographic wave drag to the model.

\subsection{First-order impact of horizontally varying stratification}

Fig. 4a displays the amplitude of the $M_{2}$ internal tide signature in the steric SSH of HYCOM experiment 13.1 ("Tideonly"), which is run under conditions like those in AGHS and SHA; with a horizontally uniform two-layer stratification, and no wind- and buoyancyforcing. As in AGHS and SHA, the stratification was taken from typical vertical profiles in subtropical areas, which cover large areas of the world ocean. However, these stratifications are very different from those in polar regions. As Padman et al. (2006) discuss, the internal tide activity along the South Scotia Ridge of the Southern Ocean in AGHS and SHA is almost certainly unrealistically large. Fig. 4a indicates that the internal tide activity in HYCOM 13.1 (Tideonly) along the South Scotia Ridge is also large. Large internal tide activity can also be seen in AGHS, SHA, and HYCOM 13.1 (Tideonly) in other polar regions e.g. the Labrador Sea and the Southern Ocean south of Africa. Fig. 4b also displays the $M_{2}$ steric SSH amplitude, but computed from one day of experiment 14.0 (M2tide); the wind, buoyancy-, and $M_{2}$-forced "warm-up" experiment. In this plot internal tide activity in the polar regions is much weaker, thus demonstrating a first-order effect of horizontally varying stratification on the internal tide field. In tropical and subtropical regions the internal tide activity is generally stronger in the wind-plustides simulation (Fig. 4b) than in the tide-only simulation (Fig. 4a).

a

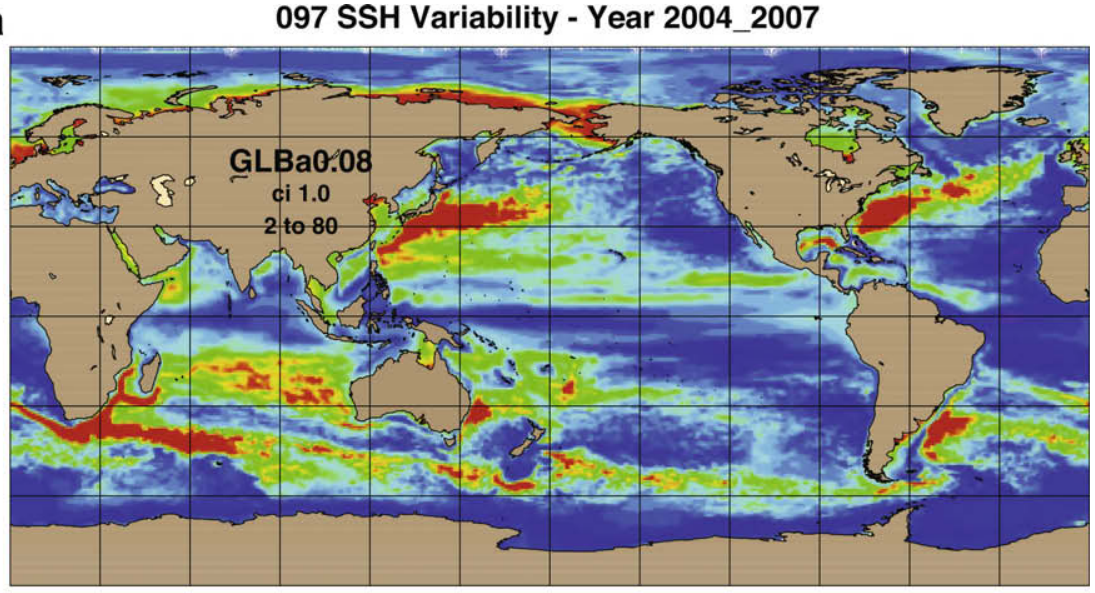

\begin{tabular}{|lllllllllll|}
\hline 0 & $n$ & $\rightarrow$ & 0 & $\infty$ & $\overrightarrow{0}$ & $\vec{N}$ & $\vec{D}$ & $\vec{\sigma}$ & $\vec{\infty}$ & 0 \\
\hline
\end{tabular}

b

141 SSH Variability - Year 2004_2007
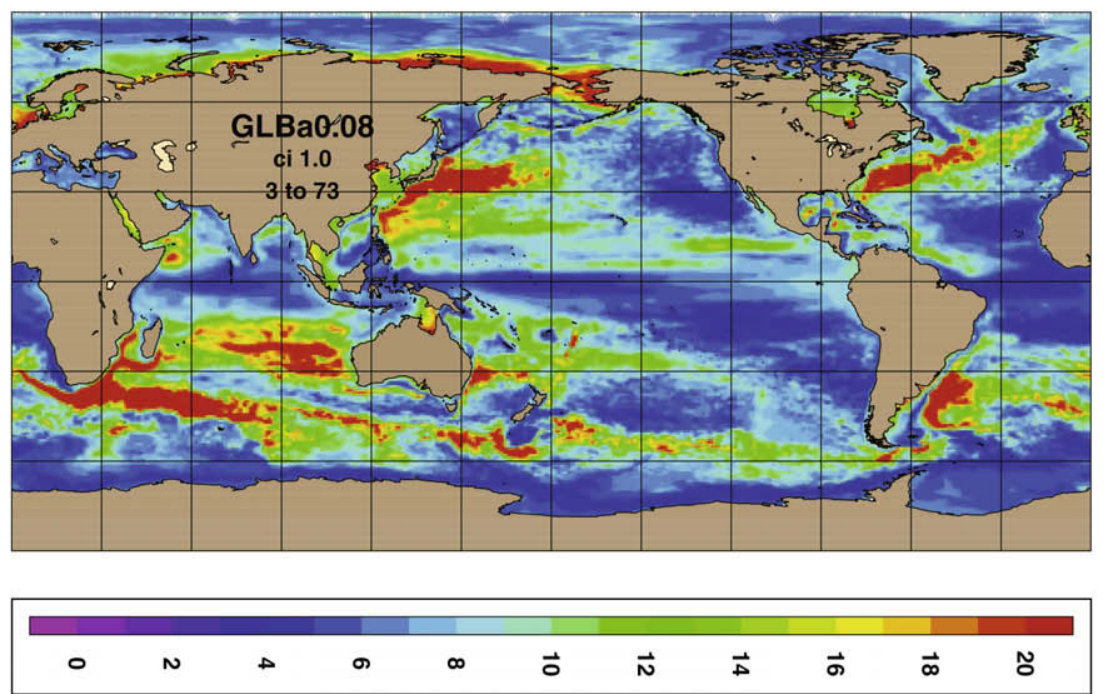

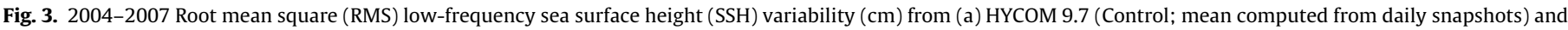
(b) HYCOM 14.1 (Alltides; mean computed from daily 25-h averages). 

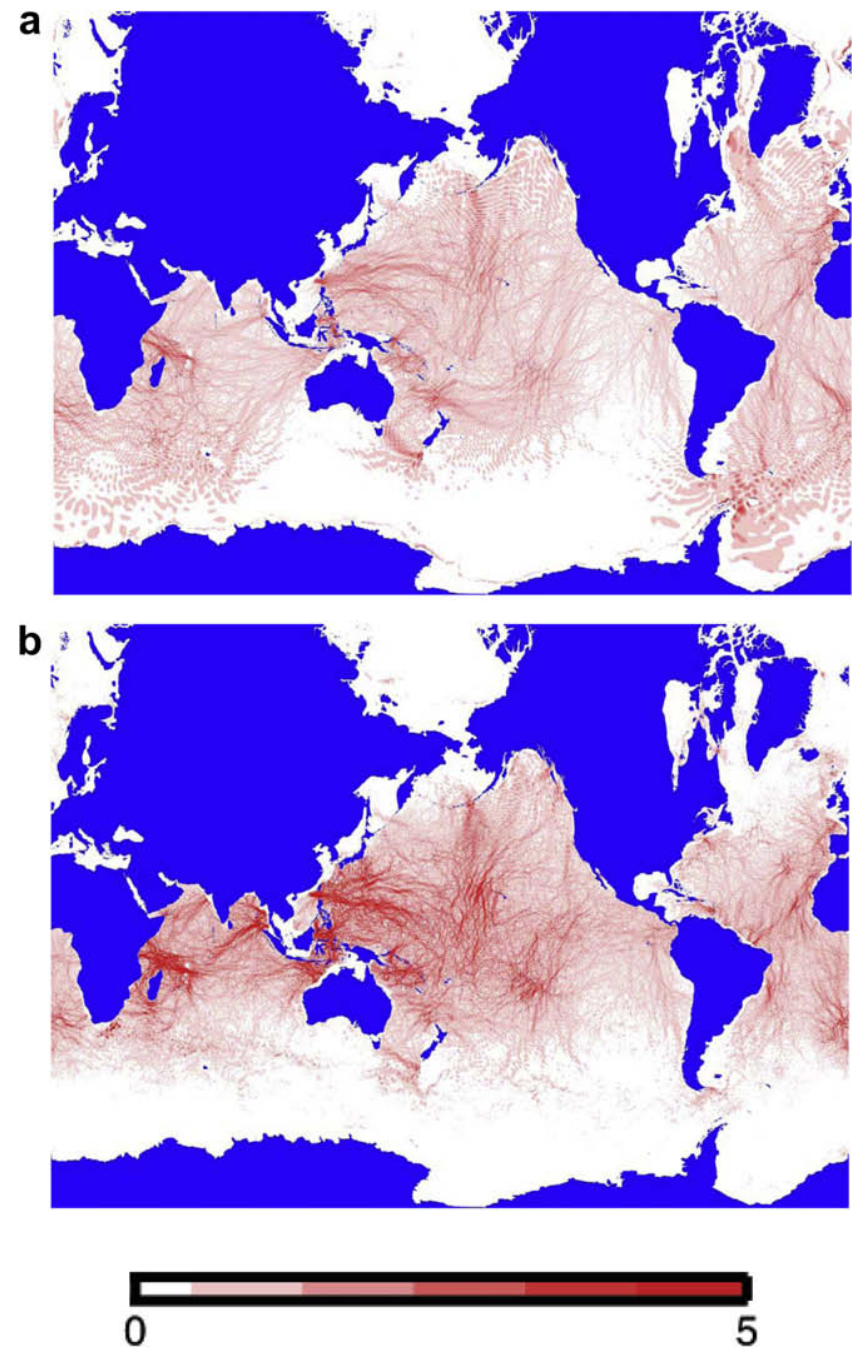

Fig. 4. Amplitude (cm) of $M_{2}$ internal tide signature in steric SSH of HYCOM experiment (a) 13.1 (Tideonly; two-layer, horizontally uniform stratification, $M_{2}$ forcing only), (b) 14.0 (M2tide; short warm-up run for 14.1; 32-layer, horizontally non-uniform stratification, wind-, buoyancy-, and $M_{2}$-forcing included.)

\subsection{Comparison of modeled internal tide to satellite altimeter data}

We now compare the modeled sea surface signature of internal tides in the vicinity of Hawai'i to the signatures seen in along-track satellite altimeter data. The altimeter data was obtained by personal communication with Richard Ray in 2006, and is an updated version of the data reported on by Ray and Mitchum (1996, 1997). Fig. 5 shows the altimeter tracks used in the comparison. The blue lines in Fig. 6 show the $M_{2}$ elevation amplitudes and phases along track number 125, in observations and in HYCOM 14.0 (M2tide). The red lines denote the low-pass filtered (barotropic) versions of the full (blue lines) signal. In Fig. 7 we display the difference between the blue and red lines in Fig. 6, i.e. the perturbations to the $M_{2}$ elevation amplitudes and phases at the sea surface due to internal tides. The peaks and troughs in the modeled perturbations clearly have similar amplitude and horizontal length scale to those in the observed perturbations, but equally clearly do not match the peaks and troughs in the observed perturbations along the entire track length, especially far from the source at Hawai'i. In contrast, when high-resolution regional models forced at their horizontal boundaries by altimeter-derived tidal amplitudes are compared to altimeter data (e.g. Carter et al., 2008 and references therein, among several), the comparison is better. The RMS of the internal

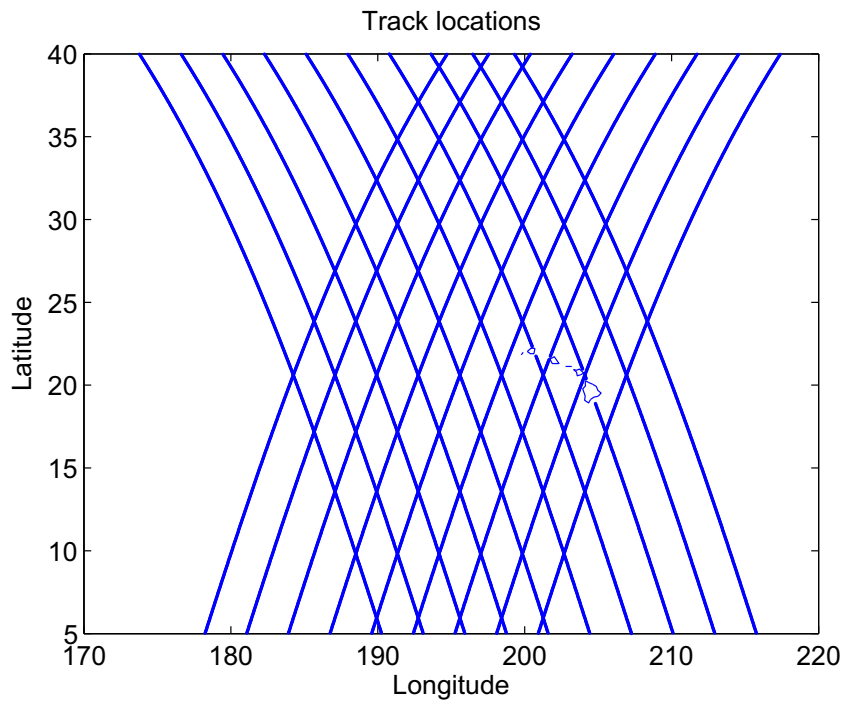

Fig. 5. Tracks for which satellite altimeter data (around Hawai'i) on surface signature of $M_{2}$ internal tides is utilized here.

tide perturbations, averaged over all of the tracks shown in Fig. 5 (using the latitude and longitude bounds shown in the Figure), are given in Table 4. RMS values are given for observations, AGHS, SHA, and HYCOM 14.0 (M2tide). The RMS of the differences between the observed and modeled perturbations (i.e. differences between the blue and red curves in Fig. 7) are given in parentheses in Table 4 . The AGHS internal tides are too weak, probably because of the relatively low $1 / 4^{\circ}$ resolution used there, as evidenced by the low RMS values compared to observations. The magnitudes of the SHA and HYCOM 14.0 (M2tide) pertubations are closer to those seen in observations, for both amplitude and phase. The poor match of the peaks and troughs in the modeled and observed perturbations is seen in the values of the RMS differences between perturbations (the parenthetical values), which are nearly as large or larger than the RMS values seen in the observations. (a) Observed amplitude

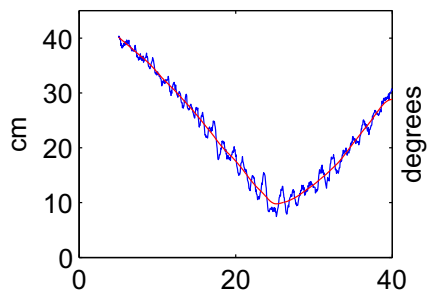

(b) HYCOM 14.0 amplitude

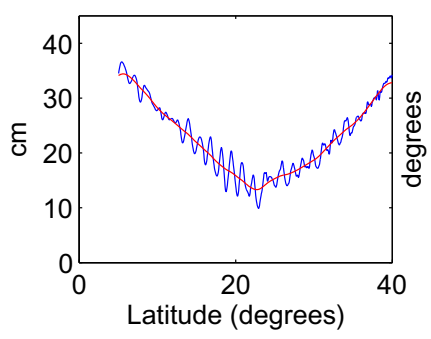

(c) Observed phase

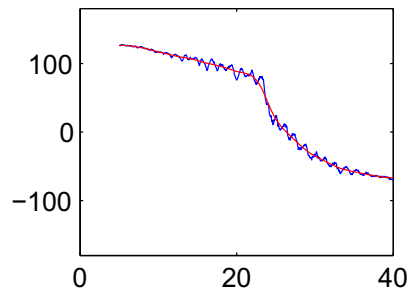

(d) HYCOM 14.0 phase
Fig. 6. Amplitudes (a, observed and b, HYCOM 14.0-M2tide) and phases (c, observed and d, HYCOM 14.0-M2tide) of the $M_{2}$ sea surface elevation along altimetric track number 125. HYCOM 14.0 (M2tide) is a 32-layer, wind-, buoyancy-, and $M_{2}$ - forced simulation. Blue lines represent full signal (barotropic plus baroclinic), red lines represent low-pass filtered (barotropic) signal. 
(a) Track 125 amplitude perturbation

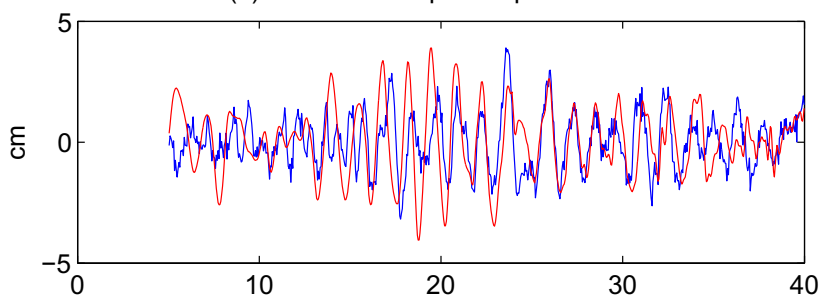

(b) Track 125 phase perturbation

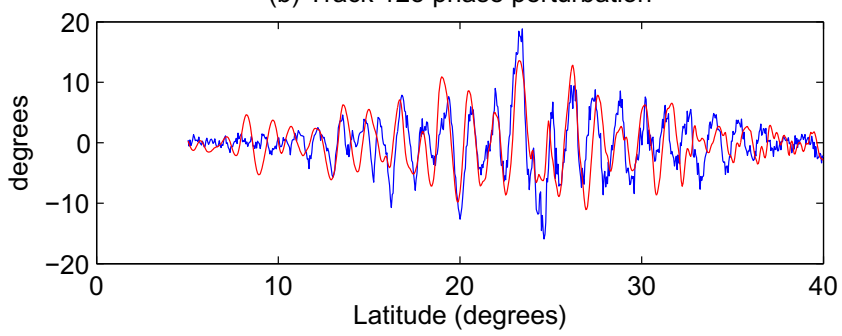

Fig. 7. Internal tide perturbations to (a) amplitude and (b) phase of $M_{2}$ sea surface elevation along altimetric track 125 . Altimetric observations are in blue, while HYCOM 14.0 (M2tide) is in red. (For interpretation of the references to colour in this figure legend, the reader is referred to the web version of this article.)
Table 4

RMS of the internal tide perturbations to $M_{2}$ sea surface elevation amplitudes and phases, computed across all of the tracks shown in Fig. 5, from altimetric observations, AGHS, SHA, and HYCOM 14.0 (M2tide). RMS values of the difference in perturbations (model minus observations) are given in parentheses.

\begin{tabular}{lll}
\hline Source & $\begin{array}{l}\text { RMS amplitude } \\
\text { perturbation }(\mathrm{cm})\end{array}$ & $\begin{array}{l}\text { RMS phase perturbation } \\
\text { (degrees) }\end{array}$ \\
\hline Observations & 0.87 & 4.35 \\
AGHS & $0.40(0.86)$ & $1.91(3.93)$ \\
SHA & $1.07(1.29)$ & $4.66(5.64)$ \\
HYCOM 14.0 (M2tide) & $1.03(1.15)$ & $4.42(4.58)$ \\
\hline
\end{tabular}

\subsection{Co-existence of tides and the eddying general circulation}

We now show some figures which visually demonstrate the coexistence of tides and the eddying general circulation in the HYCOM simulations. In Fig. 8 we show snapshots of the non-steric and steric sea-surface heights in the Southwest Pacific sector of HYCOM 14.1 (Alltides). The non-steric height (Fig. 8a) is dominated by the large-scale barotropic tide. The eddying general circulation features smaller horizontal scales and is easily discernible in Fig. 8b (the steric plot), as in many previous studies of high-resolution ocean models. Internal tides are visible as small-scale speckled patterns in the upper portion of the steric plot. It is difficult by eye to

a

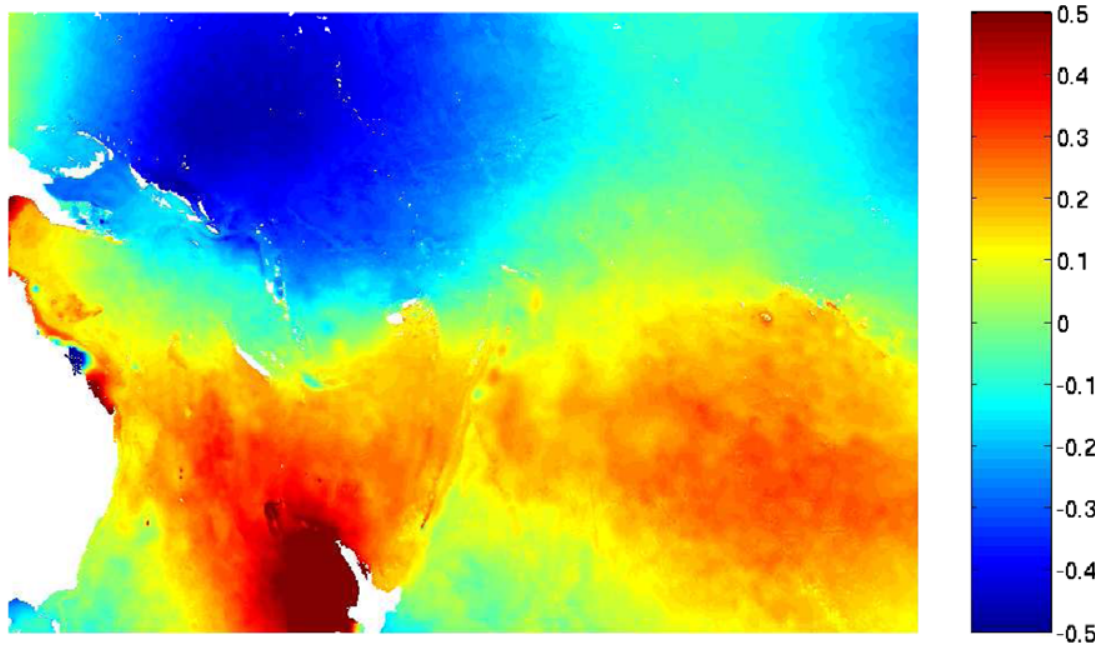

b

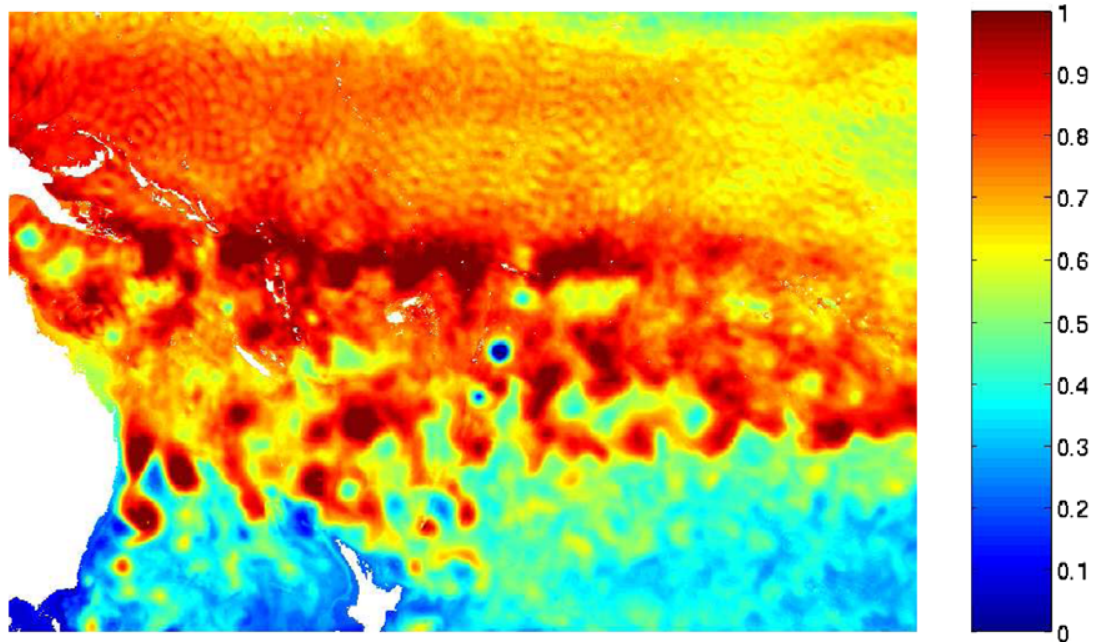

Fig. 8. Snapshot of (a) non-steric and (b) steric sea surface heights (m) in the Southwest Pacific on June 30, 2006 at 00Z, from HYCOM 14.1 (Alltides). 

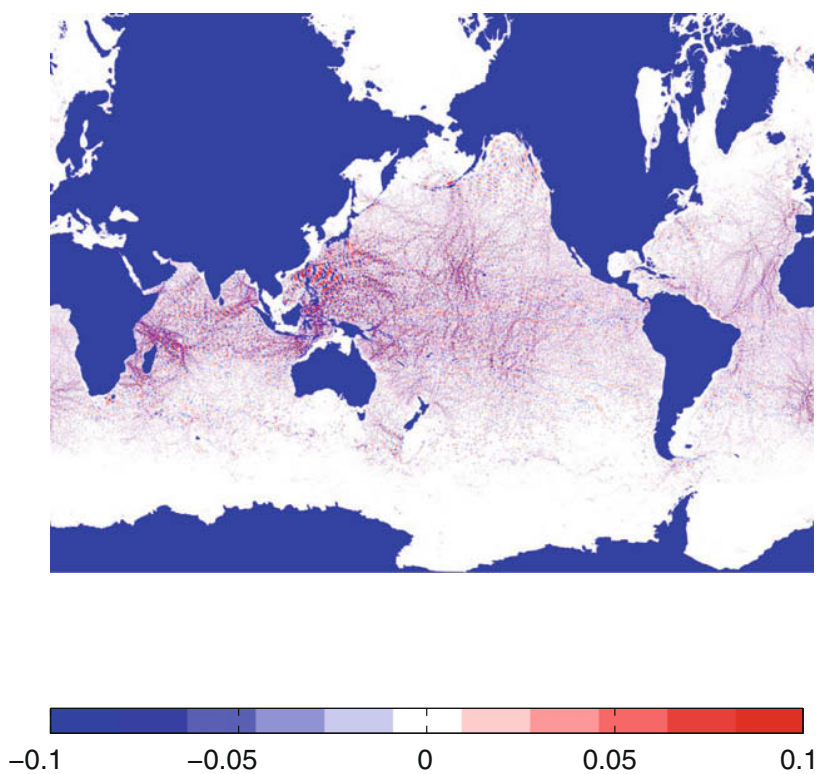

Fig. 9. Global difference in steric sea surface heights (m) from snapshots taken $6 \mathrm{~h}$ apart; June 30, 2006, 06Z-00Z, from HYCOM 14.1 (Alltides).

discern differences in steric height fields lying close together in time. A global map of differences between two steric height fields $6 \mathrm{~h}$ apart is displayed in Fig. 9. Even with a color scale that covers a range $5 \times$ smaller, the meso- and gyre-scale general circulation features in Fig. $8 \mathrm{~b}$ are absent in the difference plot. Instead, we see the much higher frequency internal tides, which show up as beams as in Fig. 4.

The co-existence of tides and the eddying general circulation can be seen more easily in animations which we have submitted along with this paper. Hawaii.fli (Supplementary mmc1.avi) shows the steric and non-steric sea surface heights in a region around $\mathrm{Ha}-$ wai'i, for the last five days of June 2004. The non-steric field, dominated by the barotropic tide, evolves rapidly in time and features large horizontal scales. In the steric field, which features smaller horizontal scales, the higher-frequency internal tide signals course rapidly through the eddying general circulation, which appears to be at a standstill on these short timescales. Stericssh.gif (Supplementary mmc2.gif), a movie of the steric SSH covering a much larger area as well as a longer time period, shows that internal tides are ubiquitous throughout the world ocean.

Finally, we give some indication of the vertical structure of the simulation in Fig. 10a and b. These figures, computed from experiment 14.1 (Alltides), display the zonal component of velocity (u) in the upper waters of a meridional section running through $\mathrm{Ha}-$ wai'i. Fig. 10b shows the 25 -h mean while Fig. 10a shows the snapshot at noon Zulu (UST). Layer interfaces are shown as solid black lines, and the thick black line is the mixed layer depth. The hybrid nature of HYCOM's vertical coordinate is illustrated by the increasing number of near-surface layers that are flat (i.e. in z-coordinates) the further north in the plot. However, the majority of the layers are isopycnal and so give an indication of the density structure. There is much more structure in the small-scale perturbations of the interfaces between isopycnal layers in Fig. 10a than in Fig. 10b, indicating that many of the perturbations are due to internal tides. These perturbations involve changes in vertical density

a

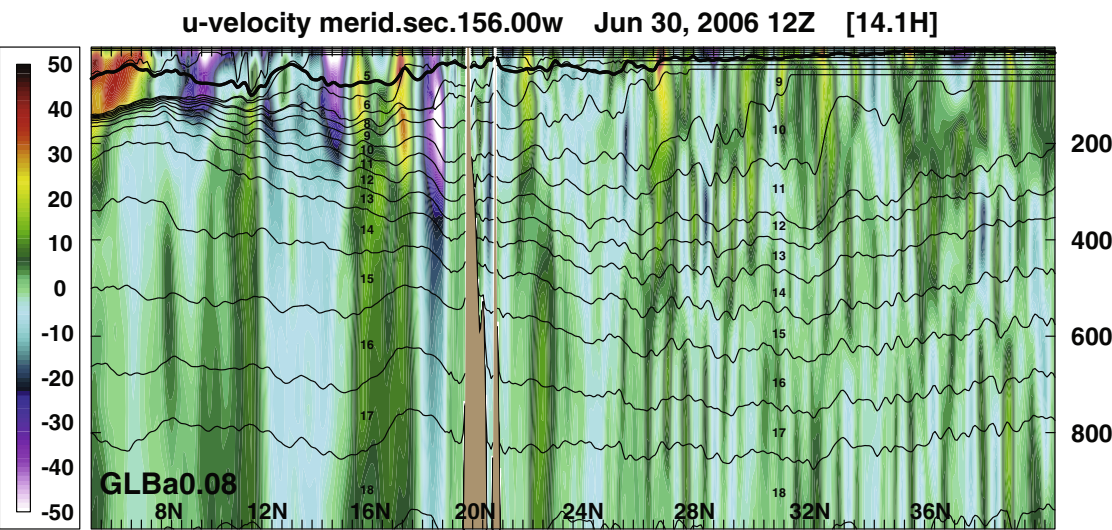

b

u-velocity merid.sec.156.00w Jun 30, 2006 MEAN [14.1H]

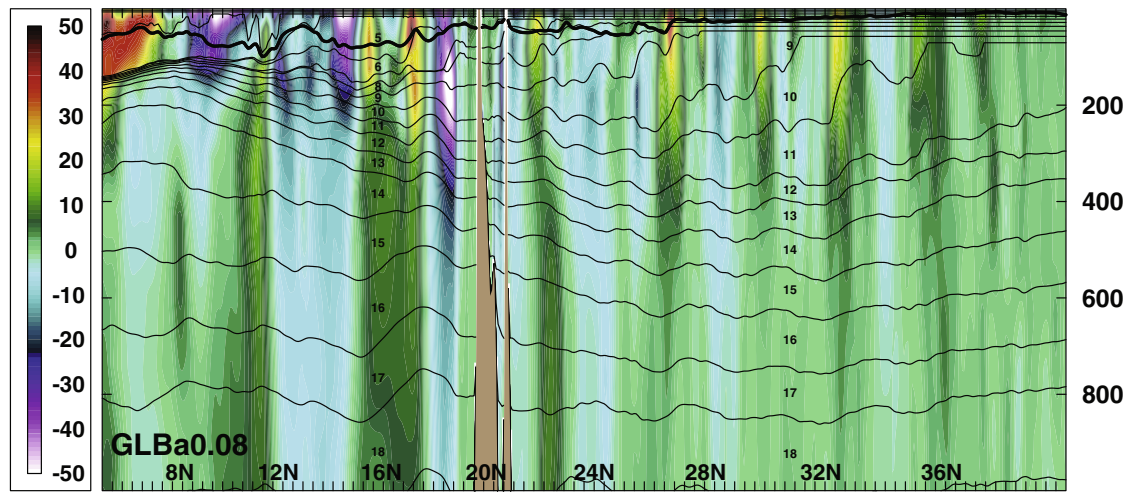

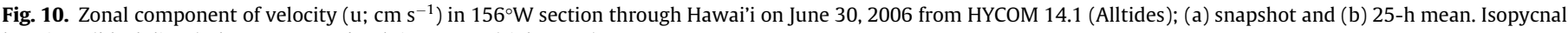
locations (black lines) shown versus depth in meters (right axes). 
structure and will have signatures in the steric SSH. Likewise, there is much more vertical structure in the velocity field in the snapshot than in the 25-h average, indicating that the tides are a strong signal, and have significant vertical structure, in that field as well.

\section{Summary and discussion}

In this paper we have shown some preliminary results of HYCOM simulations which simultaneously resolve barotropic tides, baroclinic tides, and an eddying general circulation. The nominal horizontal resolution of the simulation is $1 / 12.5^{\circ}$, and there are 32 hybrid layers in the vertical direction. We have shown that a parameterized topographic wave drag can be inserted which yields a reasonably accurate sea surface elevation of the barotropic tide at the same time that the near-bottom flows of non-tidal motions, and low-frequency SSH variability, are not strongly affected. The barotropic tide in the baroclinic simulations presented here is of comparable accuracy to that in the main baroclinic simulations of Arbic et al. (2004 - AGHS), and is considerably more accurate than that in the main baroclinic simulation of Simmons et al. (2004 - SHA).

The stratification in the simulations presented here can vary in the horizontal direction, since wind- and buoyancy forcing is present to support such variations. In contrast, the stratification in the earlier global baroclinic tide simulations of AGHS and SHA, which did not include wind- and buoyancy-forcing, was horizontally uniform. In AGHS and SHA a typical midlatitude stratification was used throughout the entire globe, and internal tide activity in some polar regions (for instance, the Scotia Sea) was almost certainly artificially high (Padman et al., 2006). Comparison of the internal tide signature at the sea surface in HYCOM runs with a horizontally uniform stratification and tidal forcing only versus the more realistic horizontally varying stratification in a wind, buoyancy, and tidally forced run, indicates that internal tide activity in polar regions is much reduced in the latter compared to the former. Thus the allowance of a horizontally varying stratification with the inclusion of wind- and buoyancy-forcing has a first-order effect on the internal tide field.

Preliminary comparisons of the surface signature of the $M_{2}$ internal tide in the region around Hawai'i with satellite altimeter data indicate that the internal tides in HYCOM appear to have approximately correct magnitude. Similar comparisons show that the AGHS internal tides are too weak, while the SHA internal tides are of similar amplitude to the HYCOM internal tides. Thus the HYCOM simulations presented here, unlike either the AGHS or SHA simulations, contain reasonably accurate barotropic tides, and baroclinic tides that are at least of the correct magnitude, at the same time. However, there is not in general a close match between the peaks and troughs seen in the internal tide perturbations to sea surface elevation in the observations and in the HYCOM model. In a planned future paper we will investigate the surface signature of the internal tides, and their comparison to satellite altimeter data, in much more detail.

\section{Acknowledgements}

This paper is dedicated to the memory of Peter Killworth, the founding editor of Ocean Modelling and an influential physical oceanographer. We thank Sonya Legg and two anonymous reviewers for very helpful comments leading to improvements in the manuscript. We thank Richard Ray for supplying us with the altimeter data on internal tides utilized in our Figs. 5-7 and Table 4. This work is funded by the Office of Naval Research (ONR), as part of the National Ocean Partnership Program, under the project, U.S. GODAE: global ocean prediction with the HYbrid Coordinate Ocean
Model (HYCOM). BKA acknowledges support from Naval Research Laboratory contract N000173-06-2-C003, and thanks Eric Chassignet and Harley Hurlburt for initiating this contract. EJM acknowledges support from ONR 6.1 project "Dynamics of the Indonesian Throughflow and its remote impact" under program element 61153 N. HYCOM simulations were performed under the Department of Defense High Performance Computing Modernization Program on an IBM SP POWER5+ at the Naval Oceanographic Office, Stennis Space Center, Mississippi and on a Cray XT4 at the United States Army Engineer Research and Development Center (ERDC), Vicksburg, Mississippi. This is contribution NRL/JA/7320-09-9261 and has been approved for public release.

\section{Appendix A. Supplementary data}

Supplementary data associated with this article can be found, in the online version, at doi:10.1016/j.ocemod.2010.01.007.

\section{References}

Arbic, B.K., Garner, S.T., Hallberg, R.W., Simmons, H.L., 2004. The accuracy of surface elevations in forward global barotropic and baroclinic tide models. Deep-Sea Res. II 51, 3069-3101.

Arbic, B.K., Mitrovica, J.X., MacAyeal, D.R., Milne, G.A., 2008. On the factors behind large Labrador Sea tides during the last glacial cycle and the potential implications for Heinrich events. Paleoceanography 23, PA3211. doi:10.1029/ 2007PA001573.

Arbic, B.K., Shriver, J.F., Hogan, P.J., Hurlburt, H.E., McClean, J.L., Metzger, E.J., Scott, R.B., Sen, A., Smedstad, O.M., Wallcraft, A.J., 2009. Estimates of bottom flows and bottom boundary layer dissipation of the oceanic general circulation from global high-resolution models. J. Geophys. Res. 114, C02024. doi:10.1029/ 2008JC005072.

Bell, T.H., 1975. Lee waves in stratified flows with simple harmonic time dependence. J. Fluid Mech. 67, 705-722.

Bleck, R., 2002. An oceanic general circulation model framed in hybrid isopycniccartesian coordinates. Ocean Model. 4, 55-88.

Carrere, L., Lyard, F., 2003. Modeling the barotropic response of the global ocean to atmospheric wind and pressure forcing - comparisons with observations. Geophys. Res. Lett. 30, 1275. doi:10.1029/2002GL016473.

Carnes, M.R., 2009. Description and evaluation of GDEM-V 3.0. Naval Research Laboratory report NRL/MR/7330-09-9165.

Carter, G.S., Merrifield, M.A., Luther, D.S., Becker, J.M., Katsumata, K., Gregg, M.C. Levine, M.D., Boyd, T.J., Firing, Y.L., 2008. Energetics of $M_{2}$ barotropic-tobaroclinic tidal conversion at the Hawai'ian Islands. J. Phys. Oceanogr. 38, 22052223.

Chassignet, E.P., Hurlburt, H.E., Smedstad, O.M., Halliwell, G.R., Hogan, P.J. Wallcraft, A.J., Baraille, R., Bleck, R., 2007. The HYCOM (HYbrid Coordinate Ocean Model) data assimilative system. J. Mar. Syst. 65, 60-83.

Chavanne, C., Flament, P., Carter, G., Merrifield, M., Luther, D., Zaron, E., Gurgel, K.W., in press-a. The surface expression of semi-diurnal internal tides near a strong source at Hawai'i. Part I: observations and numerical predictions. J. Phys. Oceanogr.

Chavanne, C., Flament, P., Luther, D., Gurgel, K.-W., in press-b. The surface expression of semi-diurnal internal tides near a strong source at Hawai'i. Part II: interactions with mesoscale currents. J. Phys. Oceanogr.

Egbert, G.D., Ray, R.D., 2000. Significant dissipation of tidal energy in the deep ocean inferred from satellite altimeter data. Nature 405, 775-778.

Egbert, G.D., Ray, R.D., 2003. Semi-diurnal and diurnal tidal dissipation from TOPEX POSEIDON altimetry. Geophys. Res. Lett. 30, 1907. doi:10.1029/2003GL017676.

Egbert, G.D., Ray, R.D., Bills, B.G., 2004. Numerical modeling of the global semidiurnal tide in the present day and in the last glacial maximum. J Geophys. Res. 109, C03003. doi:10.0129/2003JC001973.

Garner, S.T., 2005. A topographic drag closure built on an analytical base flux. J. Atmos. Sci. 62, 2302-2315.

Gill, A.E., 1982. Atmosphere-Ocean Dynamics. Academic Press, San Diego. 662 pp.

Goff, J.A., Arbic, B.K., 2010. Global prediction of abyssal hill roughness statistics for use in ocean models from digital maps of paleo-spreading rate, paleo-ridge orientation, and sediment thickness. Ocean Model. 32, 36-43. doi:10.1016/ j.ocemod.2009.10.001.

Griffiths, S.D., Peltier, W.R., 2008. Megatides in the Arctic Ocean under glacial conditions. Geophys. Res. Lett. 35, L08605. doi:10.1029/2008GL033263.

Griffiths, S.D., Peltier, W.R., 2009. Modelling of polar ocean tides at the Last Glacial Maximum: Amplification, sensitivity, and climatological implications. J. Climate 22, 2905-2924

Hallberg, R., Rhines, P., 1996. Buoyancy-driven circulation in an ocean basin with isopycnals intersecting the sloping boundary. J. Phys. Oceanogr. 26, 913-940.

Hendershott, M.C., 1972. The effects of solid earth deformation on global ocean tides. Geophys. J. R. Astr. Soc. 29, 389-402. 
Hibiya, T., Nagasawa, M., Niwa, Y., 2006. Global mapping of diapycnal diffusivity in the deep ocean based on the results of expendable current profiler (XCP) surveys. Geophys. Res. Lett. 33, L03611. doi:10.1029/2005GL025218.

Jayne, S.R., St. Laurent, L.C., 2001. Parameterizing tidal dissipation over rough topography. Geophys. Res. Lett. 28, 811-814.

Kållberg, P., Simmons, A., Uppala, S., Fuentes, M., 2004. ERA-40 Project Report Series, the ERA-40 archive. 17, 31 pp, U.K.

Kara, A.B., Wallcraft, A.J., Martin, P.J., Pauley, R.L., 2009. Optimizing surface winds using QuikSCAT measurements in the Mediterranean Sea during 2000-2006. J. Mar. Syst. 78, S119-S131. doi:10.1016/j.jmarsys.2009.01.020.

Large, W.G., McWilliams, J.C., Doney, S.C., 1994. Oceanic vertical mixing: a review and a model with a nonlocal boundary layer parameterization. Rev. Geophys. $32,363-403$.

Lee, M.-M., Nurser, A.J.G., Coward, A.C., de Cuevas, B.A., 2007. Eddy advective and diffusive transports of heat and salt in the Southern Ocean. J. Phys. Oceanogr. 37, 1376-1393.

Lyard, F., Lefevre, F., Letellier, T., Francis, O., 2006. Modelling the global ocean tides: modern insights from FES2004. Ocean Dyn. 56, 394-415. doi:10.1007/s10236006-0086-x.

Maltrud, M.E., McClean, J.L., 2005. An eddy resolving global $1 / 10^{\circ}$ simulation. Ocean Model. 8, 31-54

Marshall, D.P., Naveira-Garabato, A.C., 2008. A conjecture on the role of bottomenhanced diapycnal mixing in the parameterization of geostrophic eddies. J. Phys. Oceanogr. 38, 1607-1613.

Masumoto, Y., Sasaki, H., Kagimoto, T., Komori, N., Ishida, A., Sasai, Y., Miyama, T. Motoi, T., Mitsudera, H., Takahashi, K., Sakuma, H., Yamagata, T., 2004. A fiftyyear eddy-resolving simulation of the World Ocean-Preliminary outcomes of OfES (OGCM for the Earth Simulator). J. Earth Simul. 1, 35-56.

Murray, R.J., 1996. Explicit generation of orthogonal grids for ocean models. J. Comp. Phys. 126, 251-273.

Naveira-Garabato, A.C., Polzin, K.L., King, B.A., Heywood, K.J., Visbeck, M., 2004 Widespread intense turbulent mixing in the Southern Ocean. Science 303, 210 213.

NAVOCEANO, 2003. Database description for the generalized digital environmental model (GDEM-V) Version 3.0, OAML-DBD-72, Stennis Space Center, Mississippi $34 \mathrm{pp}$.

Nikurashin, M., 2008. Radiation and dissipation of internal waves generated by geostrophic motions impinging on small-scale topography. Ph.D. thesis, Masssachusetts Institute of Technology/Woods Hole Oceanographic Institution Joint Program.

Padman, L., Howard, S., Muench, R., 2006. Internal tide generation along the South Scotia Ridge. Deep-Sea Res. II 53, 157-171. doi:10.1016/j.dsr2.2005.07.011.

Polzin, K.L., Toole, J.M., Ledwell, J.R., Schmitt, R.W., 1997. Spatial variability of turbulent mixing in the abyssal ocean. Science 276, 93-96.
Park, J.-H., Watts, D.R., 2006. Internal tides in the Southwestern Japan/East Sea. J. Phys. Oceanogr. 36, 22-34.

Rainville, L., Pinkel, R., 2006. Propagation of low-mode internal waves through the ocean. J. Phys. Oceanogr. 36, 1220-1237.

Ray, R.D., 1998. Ocean self-attraction and loading in numerical tidal models. Marine Geodesy 21, 181-192.

Ray, R.D., 1999. A global ocean tide model from TOPEX/POSEIDON altimetry: GOT99.2, National Aeronautics and Space Administration Technical Memorandum, NASA/TM-1999-209478, 58 pp.

Ray, R.D., Mitchum, G.T., 1996. Surface manifestation of internal tides generated near Hawai'i. Geophys. Res. Lett. 23, 2101-2104.

Ray, R.D., Mitchum, G.T., 1997. Surface manifestation of internal tides in the deep ocean: observations from altimetry and tide gauges. Prog. Oceanogr. 40, 135162

Rosmond, T.E., Teixeira, J., Peng, M., Hogan, T.F., Pauley, R., 2002. Navy Operational Global Atmospheric Prediction System (NOGAPS): Forcing for Ocean Models. Oceanography 15, 99-108.

Schiller, A., Fiedler, R., 2007. Explicit tidal forcing in an ocean general circulation model. Geophys. Res. Lett. 34, L03611. doi:10.1029/2006GL028363.

Shriver, J.F., Hurlburt, H.E., Smedstad, O.M., Wallcraft, A.J., Rhodes, R.C., 2007. 1/32 real-time global ocean prediction and value-added over $1 / 16^{\circ}$ resolution. J. Mar. Syst. 65, 3-26.

Shum, C.K., Woodworth, P.L., Andersen, O.B., Egbert, G.D., Francis, O., King, C., Klosko, S.M., Le Provost, C., Li, X., Molines, J.-M., Parke, M.E., Ray, R.D., Schlax, M.G., Stammer, D., Tierney, C.C., Vincent, P., Wunsch, C.I., 1997. Accuracy assessment of recent ocean tide models. J. Geophys. Res. 102, 25173-25194.

Simmons, H.L., Hallberg, R.W., Arbic, B.K., 2004. Internal wave generation in a global baroclinic tide model. Deep-Sea Res. II 51, 3043-3068.

Simmons, H.L., 2008. Spectral modification and geographic redistribution of the semi-diurnal internal tide. Ocean Model. 21, 126-138. doi:10.1016/ j.ocemod.2008.01.002.

Smith, W.H.F., Sandwell, D.T., 1997. Global sea floor topography from satellite altimetry and ship depth soundings. Science 277, 1956-1962.

Uehara, K., Scourse, J.D., Horsburgh, K.J., Lambeck, K., Purcell, A.P., 2006. Tidal evolution of the northwest European shelf seas from the Last Glacial Maximum to the present. J. Geophys. Res. 111, C09025. doi:10.1029/2006JC003531.

Willebrand, W., Barnier, B., Boning, C., Dieterich, C., Killworth, P.D., Le Provost, C., Jia, Y., Molines, J.-M., New, A.L., 2001. Circulation characteristics in three eddypermitting models of the North Atlantic. Prog. Oceanogr. 48, 123-161. doi:10.1016/S0079-6611(01)00003-9.

Zaron, E.D., Chavanne, C., Egbert, G.D., Flament, P., 2009. Baroclinic tidal generation in the Kauai Channel inferred from high-frequency radio Doppler current meters. Dyn. Atmos. Oceans 48, 93-120. doi:10.1016/j.dynatmoce.2009.03.002. 